\title{
Knowledge and Skills for Social Workers on Mobile Crisis Intervention Teams
}

\author{
Amar Ghelani ${ }^{1,2}$ (1) \\ Accepted: 26 October 2021 / Published online: 15 November 2021 \\ (c) The Author(s), under exclusive licence to Springer Science+Business Media, LLC, part of Springer Nature 2021
}

\begin{abstract}
Public outrage over police-involved deaths of people in mental health crisis has prompted governments to expand access to crisis services that partner police with social workers. Mobile Crisis Intervention Teams (MCIT) offer assessment and support for people in distress while averting escalation. Little attention has been given to the requisite competencies for social workers on MCITs. This narrative review, informed by crisis theory and the author's experience as an MCIT social worker, provides a roadmap of knowledge and skills to familiarize practitioners, educators, and students with this growing intervention model. Social workers on MCITs should have the capacity to engage complex clients, de-escalate tension, assess for risk, plan for safety, provide brief addiction counselling, diffuse interpersonal conflict, link clients with community resources, advocate for change, challenge systemic racism, build constructive relationships, and document services with awareness of relevant legislation. The role of social workers on MCITs is multifaceted and requires attention to balancing client well-being, client safety, and community safety. The practice insights discussed in this article are relevant to preventing harm and loss of life while facilitating engagement between clients and mental health services.
\end{abstract}

Keywords Crisis intervention · Mobile Crisis Intervention Team $\cdot$ MCIT $\cdot$ Crisis outreach and response $\cdot$ COAST $\cdot$ Mental health $\cdot$ Community social work $\cdot$ Multidisciplinary interventions

\section{Introduction}

Mental health problems are a factor in as many as 1 in 2 fatal law enforcement encounters in America and the risk of being killed during a police incident is 16 times higher for those with untreated mental illness (Fuller et al., 2015). In Canada, over $70 \%$ of deaths by police involve people with mental health concerns (Marcoux \& Nicholson, 2018; Statistics Canada, 2015). Black, Indigenous, and racialized populations are overrepresented in these tragic occurrences across both Canada and the United States (ACLU, 2020; Singh, 2020). Public outrage over police-involved deaths has put pressure on governments to increase access to alternative crisis services that partner police officers with mental health clinicians such as registered social workers or nurses

Amar Ghelani

ghe10820@mylaurier.ca; amarghelani@gmail.com

1 Faculty of Social Work, Wilfrid Laurier University, Kitchener, ON, Canada

2 Health and Counselling Centre, University of Toronto, Toronto, Canada
(Adhopia, 2020; Bretneff, 2020; Bronskill, 2020; Houghton, 2021; Ling, 2020; Owen, 2020; Sam, 2020). These services, known as Mobile Crisis Intervention Teams (MCIT), provide assessment, support, and referrals for people in mental health crisis while averting escalation and use of force (Lamanna et al., 2015). In regions ranging from Toronto to Montana, politicians and police services are moving forward with the expansion of these programs to better meet the needs of people in crisis (Houghton, 2021; Toronto City Council, 2020). Although the competencies police require to respond to mental health crises have been studied extensively (see Iacobucci, 2014; IACP, 2016; Usher et al., 2019), little attention has been given to the requisite skills for social workers on MCITs in the existing crisis and social work literature. This review article will provide a roadmap of essential knowledge and skills for social work practitioners, educators, and students interested in this timely and growing intervention model. 


\section{Background}

The need for MCITs and the modern role of police as emergency responders for people in mental health crisis emerged in the 1970s and 1980s as a product of the deinstitutionalization movement (Iacobucci, 2014; Lord \& Bjerregaard, 2014). As North American governments cut mental health spending and shuttered unsafe psychiatric facilities, resources proposed for community programs were insufficient or failed to materialize (Chaimowitz, 2012; Fuller et al., 2015). Significant numbers of people with severe and persistent mental illnesses were left without adequate housing, treatment, income, or social support systems. These gaps in care facilitated the disproportionate representation of people with mental illness in interactions with police and their subsequent criminalization (Chaimowitz, 2012; Morabito, 2007). Today, 1 in 10 law enforcement interactions in the United States involve a person with significant mental health concerns (Fuller et al., 2015) and the Royal Canadian Mounted Police respond to approximately 10,000 mental health calls monthly (Tunney, 2020a).

Estimates suggest there are over 1000 mobile crisis programs worldwide, with significant variations in makeup and implementation (Watson \& Fulambarker, 2012). The American Crisis Intervention Team (CIT) model is the most prevalent, relying on specially trained police-only teams who partner with community, health, and advocacy organizations to redirect individuals with mental illness from judicial systems to health care systems (Dupont et al., 2007; Usher et al., 2019). The first CIT, developed in Memphis, Tennessee in 1988, emphasized the training of police officers in the areas of mental health, de-escalation techniques, and collaboration with mental health services to facilitate referrals and transport of people in crisis to psychiatric centers (Watson \& Fulambarker, 2012). The CIT structure is considered a 'best practice', though there is little evidence supporting its efficacy in improving client or community outcomes and some have suggested that the model has been misapplied by many police services (Watson et al., 2017; Westervelt, 2020). Non-police affiliated mobile crisis units offer an alternative for people in distress who may not be comfortable with police-only responses and are available in States such as Arizona, Georgia, California, New York, and Texas (BEAM, 2017). The most popular is the 30 year old Crisis Assistance Helping Out On the Streets (CAHOOTS) program, which originated in Eugene, Oregon to improve the city's response to mental illness, homelessness, and addiction (Climber \& Gicker, 2021). This model partners a social worker with a nurse or paramedic to respond to nonemergency, mental health-related 911 calls, and has been expanded to numerous cities such as Denver, Oakland, Portland, Olympia, and others (Climber \& Gicker, 2021). The Los Angeles Police Department was first American force to embed mental health clinicians with officers for on-site interventions in the Systemwide Mental Assessment Response Team (SMART), though Montana, Austin, and other regions have followed with their own unique crisis intervention formations (Houghton, 2021).

These police and mental health worker co-response services have a long history and are more widely accessible in Canada (Iacobucci, 2014). Vancouver's 'Car 87' was Canada's first co-response program in 1987 (Vancouver Police Department, 2020), with Hamilton's Crisis Outreach and Response Team (COAST) following in 1997 (CMHA Ontario, 2014). These programs, as well as Toronto's MCIT, offer secondary responses to crises and are called by attending officers to address complex mental health situations. In 2013, Hamilton introduced the first primary co-response team for 911 calls with a mental health component (CMHA Ontario, 2014). In Toronto and Vancouver, psychiatric nurses affiliated with local hospitals are preferred while registered social workers, occupational therapists, and nurses are utilized in Hamilton, Peel, and other regions (Lamanna et al., 2015). As demand for these services intensify, social workers are likely to be called upon to meet the growing need.

Outcome studies evaluating the efficacy of MCITs are scarce, though the few available studies show promising results (Bailey et al., 2018; Blais et al., 2020; Kirst et al., 2015; Kisely et al., 2010; Lamanna et al., 2015; Semple et al., 2020). A systematic review found co-responder crisis models can reduce the number of mental health act apprehensions and use of police custody for people with mental illness (Puntis et al., 2018). The Sherbrooke, Quebec MCIT demonstrated effectiveness in reducing police use of force, connecting distressed individuals with community services, and avoiding unnecessary emergency department (ED) visits (Blais et al., 2020). A co-response team in Indianapolis was found to reduce short term incarceration risk (Bailey et al., 2018). Toronto's MCIT was found to have lower rates of injury, arrest, and involuntary escort to hospital compared with police-only teams (Lamanna et al., 2018). An evaluation of the South Simcoe MCIT also reported decreased involuntary apprehensions compared with general patrol officers (Semple et al., 2020). MCITs are a small but valued component of a broader crisis system, and most clients and stakeholders appear to agree this approach is more appropriate than police-only teams in responding to moderate to severe mental health crises (Kirst et al., 2015).

A mental health crisis is an "acute disruption of psychological homeostasis in which one's usual coping mechanisms fail and there exists evidence of distress and functional impairment" (Roberts \& Ottens, 2005, p. 331). For 
the purpose of this paper, a 'person in crisis' or 'client' is an individual "whose behavior brings them into contact with police either because of an apparent need for urgent care within the mental health system" or because they are acting in a manner that is "sufficiently erratic, threatening, or dangerous" that police are called to protect them or those around them (Iacobucci, 2014, p. 49). Training programs for CIT's and MCITs typically follow a $40 \mathrm{~h}$ structure involving didactic presentations by mental health professionals on mental illness, substance use, suicide assessment, de-escalation, psychiatric medications, and community resources, as well as role playing, site visits to local psychiatric services, and presentations from affected individuals/families (Fahim et al., 2016; Watson et al., 2017). While a comprehensive training guide for law enforcement has been published by CIT International (Usher et al., 2019) and crisis intervention skills, theory, and modalities have been described thoroughly in other publications (Dattilio \& Freeman, 2010; James \& Gilliland, 2016; Regehr, 2011; Roberts \& Ottens, 2005, Yeager \& Roberts, 2015), literature focusing specifically on social workers and MCITs is sparse, dated, and limited by lack of focus on practice skills (Patterson, 2004; Roberts, 1978; Watson \& Fulambarker, 2012).

\section{Methods}

Informed by crisis theory (Regehr, 2011; Roberts, 2000) and the author's experience as a social worker on a Canadian MCIT, this narrative review examined relevant literature to identify beneficial knowledge and skills for social workers on MCITs. A search of academic and practice-oriented literature published in English was conducted from July 2020 to September 2020. Databases such as PubMed, PsycINFO, MEDLINE, Social Work Abstracts, and Google Scholar were utilized. Search terms included mobile crisis intervention, police co-response crisis intervention, mobile crisis unit, and crisis outreach and response. Literature unrelated to crisis intervention or mental health treatment was excluded. Grey literature, including newspaper articles and reports, was searched via Google, ProQuest, and OpenGrey and included to highlight current events and context related to the subject matter.

\section{Findings}

The review of literature led to identification of the following eleven practice skills. For the purpose of this paper, the term practice skills refer to capacities required for social workers engaged in the operational activities of MCITs. This overview of skills and related knowledge is not intended to be exhaustive, but a primer for social workers to guide further learning.

\section{Engagement}

The first few minutes of interaction with a person in crisis are crucial to reviewing the reason for the meeting, setting the tone, building rapport, and gaining pertinent information (NAMI, 2016). People with serious mental illness can be difficult to engage and clients supported by MCITs typically start off ambivalent or not wanting involvement (Dixon et al., 2016). Requests for these services come from family, professionals, community members, or officers concerned about an individual's distressing and unsafe behaviors, as well as clients themselves. Manic episodes and symptoms of psychosis such as paranoia can trigger referrals to mobile crisis units and make engagement the most difficult yet vital component of crisis intervention (Coid et al., 2016; Lamanna et al., 2015). Without adequate rapport (with clients and supports) subsequent elements of an intervention become more challenging (Roberts \& Ottens, 2005).

People in crisis are known to prefer compassionate, empowering, and non-criminalizing approaches when interacting with MCIT workers (Lamanna et al., 2018). The presence of a police officer and crisis worker can be perceived as frightening and professional requirements to wear a mask and maintain distance to prevent the spread of COVID-19 can exacerbate anxiety. A clinician's demeanour, attitude, and ability to take the lead have a direct impact on reducing tension in a high-risk situation (Bretneff, 2020). Social Work skills such as reflective listening, validation, sensitivity, empathy, and encouragement, alongside recognition of client strengths and protective factors can set the basis for an engaged therapeutic connection (Marcoux \& Nicholson, 2018; NAMI, 2016). Ability to concisely explain legal caveats such as limits to confidentiality, duty to warn, risks/ benefits of engagement, and records processes are necessary to establishing trusting and ethical services (CASW, 2005a, 2005b). Knowledge of the recovery model and person-centered care, as well as a quick ability to identify therapeutic goals and needs can help develop a hopeful vision for beyond the crisis (Dixon et al., 2016).

\section{Crisis De-escalation}

De-escalation strategies are central to reducing risk for injury and death among people in crisis and responders (Iacobucci, 2014). Talking in a calm, non-confrontational tone while maintaining safe distance, using a volume lower than the client, and setting limits are all useful first steps (Saunders, 2016). Providing a sense of choice and control, such as reminding clients of their autonomy or offering options for community treatment, can enhance a sense of self-efficacy 
(Lamanna et al., 2015). Removing distractions, using a non-threatening posture, maintaining congruent body language, being consistent, using "I" statements, identifying needs, and avoiding promises one cannot keep are useful for maintaining trust while reducing distress (Saunders, 2016). Commitments to using as little non-lethal force as possible lays the foundation for an approach that recognizes the inherent value of the client's life (Iacobucci, 2014). Many people in crisis have experienced trauma, therefore elements of trauma-informed care, including safety, trustworthiness, transparency, collaboration, and incorporating client voice and choice are important for empowerment (CDC, 2018; Yeager \& Roberts, 2015). Grounding techniques or dialectical behavior therapy (DBT) skills such as distress tolerance can offer in-the-moment, evidence-informed coping strategies to strengthen internal modulation mechanisms and enhance focus on problem solving (Linehan, 2014; Najavits, 2002).

\section{Risk Assessment}

A key role of crisis workers is assessing for signs of mental distress, imminent danger, and lethality (Regehr, 2011; Roberts \& Ottens, 2005). The first six chapters of the American Psychiatric Association's (2015) 'Guidelines for Psychiatric Evaluation of Adults' offers an evidence-informed framework to steer mobile interventions and triage clients with severe mental health issues. Components include assessment of psychiatric symptoms, mental status (i.e. insight, judgement, mood, etc.), psychosocial stressors, risk of harm to self or others, past hospitalizations, self-harm history, medications, substance use patterns, family history, medical history, protective factors, and other relevant areas. Signs of psychosis such as paranoia, perceptual disturbances, delusional beliefs, blunted affect, emotional withdrawal, catatonia, and functional impairment should also be assessed. Operational knowledge of the Diagnostic and Statistical Manual of Mental Disorders 5 (American Psychiatric Association, 2013), Brief Psychiatric Rating Scale (Ventura et al., 2000), and Regehr and Glancy's (2014) social work assessment is valuable for comprehensive psychosocial assessment.

Promotion of client self-determination and autonomy are embedded in social work values and ethics (CASW, 2005b), though MCITs are sometimes legally required to overrule the wishes of people in crisis. Section 17 of the Ontario Mental Health Act (MHA), similar in provinces across Canada and the United States, gives power to police officers to apprehend individuals acting in a "disorderly manner" who have (a) threatened to "cause bodily harm" to themselves, (b) behaved "violently towards another person" or (c) shown "lack of competence to care" for themselves; and transport them to a hospital for examination by a physician (Mental Health Act, 1990, s.17). Police must be of the opinion that the person in crisis is suffering from a mental disorder that may result in serious bodily harm. This legal authority effectively makes police a type of "psychiatric ambulance" (Iacobucci, 2014, p. 100). Despite some training and expertise, police officers are not regulated mental health workers and MCITs offer a structure for appropriate professionals to advise officers.

Mobile responders are known to attend calls involving people in crisis with psychotic, mood, and/or substance use disorders who are unwilling to speak with a professional (Lamanna et al., 2015). Those presenting with acute psychosis, excited delirium, and/or paranoid ideation are statistically less likely to engage and present with higher risk for aggression, especially when under the influence of substances (Coid et al., 2016; Fazel et al., 2009; Large \& Nielssen, 2011; Takeuchi et al., 2011). Should the client in crisis not be communicative or refuse transport to an ED, a review of MHA criteria and use of the Crisis Triage Rating Scale (CTRS), for example, can determine eligibility for involuntary apprehension (Lamanna et al., 2015; Turner \& Turner, 1991). In cases of excited delirium, where people in crisis present acutely agitated and aggressive due to substance abuse, rapid sedation in a hospital setting is essential for positive outcomes (Takeuchi et al., 2011). Of the 1237 times Toronto MCITs escorted clients to an ED in 2014-2015, 19.1\% were "responder initiated" or involuntary (Lamanna et al., 2018, p. 5). These types of assessments are fluid and unpredictable, requiring open communication between officer and worker to determine a mutually agreed upon course of action. When social workers are required to override a client's wishes, they must "take care to use the minimum coercion possible" (CASW, 2005a, p. 4). Voluntary transportation to hospital is always striven for in these situations.

Crisis services routinely respond to referrals with overlapping psychosocial issues. In addition to the diagnostic categories described above, MCITs also support clients with anxiety, personality, neurocognitive, developmental, and eating disorders (Lamanna et al., 2015). Adaptability is essential, as a social worker may assess a client with severe dementia and agitation in a long term care home at the beginning of the day, develop a safety plan with a youth with panic disorder and self-harm at school by midday, then guide a family with language barriers expressing concerns about a homeless son on the autism spectrum at the end of the day. Knowledge of the developmental disabilities sector, forensic system, problems of adolescence, geriatric issues, immigration system, neurocognitive complications, and mental disorders related to medical conditions is beneficial even though these types of calls are less frequent (Regehr \& Glancy, 2014). 


\section{Safety Planning}

The development of a safety and action plan is paramount for engaged clients demonstrating non-urgent risk for selfharm (James \& Gilliland, 2016; Roberts \& Ottens, 2005). Wellness checks, where police are asked by family or community members to check-in on persons with mental health concerns, can also be enhanced through written safety plans. Reports from watchdogs identifying a concerning pattern of police use of force during wellness checks highlights the vital need for mental health professionals to lead these checks (Adhopia, 2020; Bretneff, 2020; Tunney, 2020a, 2020b). Input from family or significant supports can facilitate the process, as others may have relevant collateral information and be the primary supports after the MCIT leaves (James \& Gilliland, 2016). Conversely, providing space to decline the involvement of others after discussing confidentiality is useful to offering control and building trust.

The Zero Suicide Model is an evidence-informed prevention and intervention practice that can be applied by MCIT social workers to assess and reduce the risk associated with suicidality or self-harm (Brodsky et al., 2018). Applied Suicide Intervention Skills Training (ASIST) alongside the Suicide Intervention handbook (see Ramsay, 2004) also offer strong models for assistance, risk reduction, and safety planning. These programs emphasize screening, lethal means reduction, linkages to community services (i.e. crisis lines), using abridged CBT/DBT methods, and development of written 'safe-plans' (Brodsky et al., 2018; Ramsay, 2004). Plans are co-constructed with the client and focus on identifying triggers, signs of distress, supportive people, coping skills, safe spaces, helpful services, medications, strengths, long term goals, dates of future appointments, and activities which should be avoided (Yeager \& Roberts, 2015).

Clients with signs of psychosis who call emergency services repeatedly due to fears based in paranoid belief systems often become known to MCITs. From the author's experience, those concerned about intricate conspiracies, paranormal activity, and other unusual problems are regularly referred. In these cases, the person in crisis typically requests to speak with the officer and questioning related to mental health is perceived as an insult. Ability to hear their concerns, create a sense of safety, validate emotions, and understand the logic and meanings behind their fears, without agreeing or arguing, are important to establishing trust (Bullimore, 2013; Lego, 1984). As a relationship is built through repeated respectful encounters, clinicians can gradually identify the content of the delusional system, investigate how these thoughts are affecting the person's life, and gently introduce more adaptive coping strategies (Lego, 1984). Cognitive-behavioral approaches for psychosis such as identifying triggers, physical sensations, and goals may reveal entry points for referrals to services that can better address underlying psychosocial issues (Hagen, 2011).

\section{Conflict Resolution}

Many of the situations crisis teams encounter are related to relationship problems or family violence (Lamanna et al., 2015; Patterson \& Swan, 2019). Even when not the primary concern, family and relational challenges are intricately imbedded in many crisis situations (James \& Gilliland, 2016). A common crisis scenario involves a family conflict with an intoxicated client demonstrating high levels of emotion, behavioral dysregulation, and signs of mental illness. Police officers are typically experienced in deescalating these types of crises and social workers can support them with assessment, contingency clarification, instilling therapeutic hope, referrals to counselling, and calls to child protection services as needed (James \& Gilliland, 2016). At times, the family may request more support than the person in crisis. Evidence-informed approaches such as solution focused brief therapy (SFBT) can help maintain focus on the present, explore options for problem solving, identify small steps toward change, highlight what is working, review what worked previously, and negotiate a more positive way foreword (Franklin et al., 2011; Shazer \& Dolan, 2007). In situations where potential for violence or family breakdown is high, physical transportation to a shelter or safe house may be necessary (James \& Gilliland, 2016). Intimate partner violence represents close to one third of all violent crime reported to police, with women accounting $79 \%$ of the victims and women of color over-represented (Conroy et al., 2019). In circumstances with escalation or history of intimate partner violence, actual or pending separation, and/or intuitive sense of fear on the part of the victim, crisis workers must assess for homicide risk, as $60 \%$ of intimate partner homicides are preceded by past family violence (Conroy et al., 2019; Dawson \& Piscitelli, 2017). The most common characteristics of domestic homicide perpetrators are obsessive behavior, depression, suicide threats/attempts, threats to kill the victim, unemployment, attempts to isolate the victim, and substance abuse (Dawson \& Piscitelli, 2017). Social workers can help prevent escalation of unstable situations by expressing concerns about safety, contingency planning, and linkages to services specializing in intimate partner violence. Utilizing a culturally-aware, systems model of assessment and care, alongside validation and pragmatic planning, can help diffuse interpersonal conflict while guiding distressed families toward options for resolution (Regehr \& Glancy, 2014). 


\section{Brief Addiction Counselling}

Problems related to substance abuse are prevalent among people in crisis (Lamanna et al., 2015). These challenges can include withdrawal syndrome, concerns about relapse, overdose prevention, amotivation, and disruptive behaviors related to acute intoxication. Knowledge of the effects of street drugs, addiction, drug interactions with medications, polysubstance use disorder, substance-induced psychosis, and concurrent disorders is recommended when conducting substance-related interventions. The transtheoretical model (also known as stages of change) can help assess motivation for change and tailor interventions to meet client needs (Prochaska et al., 2007). Motivational interviewing techniques are shown to address ambivalence and encourage movement toward recovery (Miller \& Rollnick, 2012). Clients in the precontemplation or contemplation stages of change can benefit from harm reduction strategies that offer choices for minimizing risks associated with substance use (CMHA Ontario, 2018). Those already in recovery may require an updated relapse prevention plan to keep focused on long-term goals. For clients wanting to discontinue substance use, knowledge of withdrawal management, outpatient services, and treatment options is essential (Bailey et al., 2018). Since March 2020, many rehabilitation programs have slowed or moved online to prevent the spread of COVID-19, requiring workers to maintain viable service partnerships and up-to-date awareness of referral processes to effectively connect marginalized clients with the programs they need to survive (Armstrong, 2020).

\section{Housing and Community Referrals}

An evaluation of Toronto MCITs found $6.3 \%$ of referrals were related to housing, $12.5 \%$ of clients were homeless, and $11.5 \%$ resided in supportive housing (Lamanna et al., 2015). While housing systems and client needs vary across localities, knowledge of shelters, housing programs, and referral processes are key to short term resolution of housing crises. Many of the problems clients experience are exacerbated by material conditions of poverty and referrals to income supports, food banks, employment programs, and others can alleviate socioeconomic stressors (Regehr \& Glancy, 2014). Ability to match clients with appropriate community services can prevent hospitalizations and incarcerations while enhancing the quality of care received in the community (Lord \& Bjerregaard, 2014). An evolving awareness of specialized services such as Housing First, Early Psychosis Intervention, and Mental Health and Justice Case Management can increase the efficacy of interventions. Similar to addictions referrals, formal partnerships, informal collaborations, and streamlined communications among participating agencies are valuable to ensuring clients in crisis are not in the same position the next day (Bailey et al., 2018; Lamanna et al., 2015).

\section{Advocacy}

Stigma related to mental illness in the forms of prejudice, stereotypes, and discrimination can impact access to health care, safe housing, and employment (Corrigan \& Watson, 2002). Structural stigma describes the systematic exclusion of people with mental illness from full participation in civic and social life (Livingston, 2013). Social workers have an obligation to promote social justice and equitable distribution of resources through reducing barriers to care and expanding choice for marginalized groups (CASW, 2005a). Affordable and supportive housing is in short supply across North America, though stable housing is crucial to mental well-being (FCM, 2020). When people with mental illness are released from hospitals or prisons, adequate housing, income, and community treatment supports are needed to prevent costly repeat crises (Torrey et al., 2017). Crisis workers are in unique positions of power and can identify gaps in community support systems through repeated requests for assistance. Social workers need to be able to advocate for individual clients at community tables while lobbying institutional leaders to adequately resource organizations supporting people with mental illness (Livingston, 2013; Torrey et al., 2017).

Challenging stigma also involves advocating against practices that misrepresent people with mental illness. For example, it is standard protocol for police on MCITs to handcuff those apprehended under the Mental Health Act when escorting to hospital (Iacobucci, 2014). This practice assumes the potential for violence or flight and appears to criminalize people with mental illness who have committed no crime and are not under arrest (Lamanna et al., 2015). While some clients with acute psychosis, agitation, or intoxication can present elevated risk, a definitive causal relation between mental illness and violence has not been established and the vast majority of people with mental illness are no more likely to engage in violent behavior than the general population (CMHA Ontario, 2012). Not only can hand-cuffing stigmatize clients, it erodes trust and escalates crisis. In line with recommendations from previous reports, social workers must advocate for more clinical discretion in situations where handcuffing may not be necessary (Iacobucci, 2014; Lamanna et al., 2015).

\section{Challenging Systemic Racism}

The historic and ongoing impact of systemic racism on people of color in the United States and Canada have been well-documented (Boyd, 2001; Fry et al., 2018; O'Neill, 2020; OHRC, 2020b; Solly, 2020; Solomon et al., 2019; 
TRC, 2015). Racial bias in policing is particularly problematic, as Black and Indigenous peoples are over-represented in police arrests, charges, use of force, and killings (Desilver et al., 2020; Maynard, 2017; OHRC, 2020a). Systemic racism reflects deeply embedded assumptions about how society should function and structurally subjects people of color to discriminatory treatment (Hughes, 2020). Intersecting stigmas related to race, poverty, and mental illness can magnify police officers' perception of risk and potentially contribute to use of force (Bretneff, 2020). In hospitals and community health services, too many people of color are experiencing barriers to care, inadequate care, degrading treatment, or excessively coercive interventions (Allan \& Smylie, 2015; Halwani, 2004). Workers on MCITs have an ethical responsibility to challenge entrenched patterns of systemic and interpersonal racism.

Anti-oppressive social work practice emphasizes reducing power imbalances between social service users and providers while recognizing the intersecting forms of oppression inherent in health, criminal justice, and social welfare systems (Mullaly \& Dupré, 2018). Concrete steps can include opposing racist practices (such as carding or use of excessive force), advocating for equitable treatment of racialized groups, and protecting people in crisis from harm (CASW, 2005a). MCIT social workers must also acknowledge racism exists, observe personal biases, reflect on privilege and power, be aware of how racism affects service delivery, avoid coercive tactics, and fight for individuals falling through gaps in societal systems (CASW, 2005b).

\section{Relationship Building}

The ability to develop and maintain constructive and respectful relationships with people in crisis, police, families, and a range of community partners, sometimes with explicitly competing interests, is a hallmark of this role. For example, a family may want their loved one hospitalized due to acute psychosis, hospital staff may prefer community diversion due to limited bed availability, officers on scene may desire an expeditious assessment, and the person in crisis may not want to speak with the team. Diplomatic balancing of these contradictory demands is challenging in even the most straightforward interventions. Capacity to empathize with all parties involved is key to communicating in a manner that develops connections. Almost 30\% of MCIT referrals in Toronto are for clients known to the program (Lamanna et al., 2015). Building trusting therapeutic relationships through balancing validation and change is critical to connecting clients with services that may help prevent perpetual disruptions in homeostasis (Linehan, 2014).

There is a dearth of literature focused on building productive relationships with police officers on MCIT's while balancing the tensions inherent in working with policing organizations that are implicated in maintaining oppressive societal structures. From the authors experience, it is important to distinguish the individual officers on MCIT's from broader institutions that perpetuate systemic racism. While social workers have a primary responsibility to support clients, officers have an added responsibility to ensure the safety of the worker. Ability to see problems from a security perspective and compliment the work of police can facilitate relational development. A sense of humor and aptitude for light conversation is not only useful for building relationships, it can help prevent burnout (Maxwell, 2003; Talbot \& Lumden, 1999). Ability to build constructive relationships with hospital and shelter staff is also valuable for problem solving and referral processes (Steadman \& Morrissette, 2016).

\section{Applied Legislation and Documentation Practices}

Mobile crisis workers require an awareness of legislation that frames their work. In Canada, this includes the Mental Health Act, Personal Health Information and Protection Act (PHIPA), the Health Care Consent Act, the Substitute Decisions Act, and the Child and Family Services Act (Iacobucci, 2014). Confidentiality is the bedrock of trusting therapeutic relationships, though these assessments can occur in settings such as coffee shops, parks, and multi-family homes where privacy is difficult to establish. Familiarity with professional guidelines around confidentiality, records, and consent allows clinicians to provide ethically sound services (OCSWSSW, 2011; Van Sickle, 2018). A duty to warn may arise when an individual poses a clear and imminent risk to an identifiable person or group, with the potential for harm resulting in severe bodily injury, death, or serious psychological harm (Betteridge, 2013). Due to the nature of the program and clientele, there is higher than usual potential for clinical records to be requested or subpoenaed. Therefore, crisis clinicians must be especially careful and precise when documenting assessments, interventions, and rationale. Comfort consulting with colleagues, supervisors, physicians, legal advisors, and professional bodies is imperative for ethically sound documentation practices.

\section{Discussion}

This article addresses a gap in the crisis intervention literature and provides social workers a roadmap of requisite knowledge and skills to offer competent care to clients supported by MCITs. Social workers have ethical responsibilities to help people in need, challenge social injustice, and continually strive to enhance their practice capabilities (NASW, 2017). The skills described in this article can aid social workers in preventing harm and loss of life while 
promoting a sense of hope for people in crisis. Social service agencies have worked alongside police for over a century (Patterson \& Swan, 2019), and the recent expansion of MCITs reflects progress in the collaboration between social workers and police toward providing more appropriate responses to mental health crises. As police organizations come under increasing pressure to reform the manner in which they engage with marginalized communities, and stop using excessive force against people in distress and people of color, social workers can be a valuable part of the reformation process (Adhopia, 2020; Ling, 2020; Owen, 2020; Reston, 2021). The skills clinicians bring to these teams are integral to elevating non-violent communication, protecting the lives of vulnerable populations, and shifting emphasis away from criminalizing distressed people of color.

Widespread anxiety related to the coronavirus pandemic has also heightened the need for more accessible crisis response programs, and social workers on MCITs present a novel avenue to meet the complex demands of a rapidly changing mental health landscape (Mereli, 2020). Many programs have moved online to prevent the spread of COVID19 (SAMHSA, 2020) and waitlists for mental health support are growing across Canada and the United States (CIHI, 2021; Mental Health in America, 2021). Unlike other services, MCITs provide prompt opportunities for clients in crisis to receive in-person assessment, triage, and guidance from a qualitied mental health care provider. Through engagement, brief counselling, referrals, and transport to suitable services, these teams bridge the divides between people seeking support and community programs offering it. The capacity to de-escalate tense situations, diffuse interpersonal conflict, and develop evidence-informed safety plans can help clients and families cope to a point where more intrusive intervention may not be necessary. Those with an identifiable mental disorder who pose a risk to harm others can be diverted away from criminal justice systems and offered the treatment they need to remain safely in the community. For clients contemplating a shortened existence, assistance with validation, community linkages, and a plan for a more hopeful future can be life-sustaining. The role of social workers on MCITs is multifaceted and involves balancing attention to client recovery, client safety, and community safety to meet the needs of clients and stakeholders in difficult circumstances.

Many social problems are beyond the capacity of a single worker, team, or program to resolve. The need for MCITs is an indicator of broader structural deficiencies (such as lack of supportive housing) that push people with mental illness into crisis. These teams act as Band-Aids to protect social wounds from infection and, due to the reactive nature of program design, typically only treat the superficial manifestations of deeply rooted societal problems like mental illness, racism, and stigma. Despite the primary responsibility to respond to the crisis at hand, social workers on MCITs must also endeavour to address systemic gaps in care for disadvantaged groups while advocating for individual client needs. A flexible, responsive, and collaborative continuum of crisis services is crucial for these teams to function effectively and achieve intended results (Steadman \& Morrissette, 2016).

As MCIT services mature, there are a number of program components that require further study before the model can be considered an evidence-informed practice. Ongoing program evaluation is essential to determining whether specific MCITs are meeting the needs of communities, families, and clients in crisis. Research is needed to understand how MCITs can better deescalate distress, promote client recovery, increase consumer and family satisfaction, and prevent repeat crises. Although some MCITs have demonstrated efficacy in improving community connections, reducing police use of force, and averting involuntary transport to hospital, more research is required to identify specific skill sets among social workers that can predict desired outcomes.

\section{Conclusion}

This article reviewed literature and skills important for social workers partnered with police in a timely and growing crisis intervention model. Eleven practice skills were identified for social workers, students, and educators to enhance competence and guide further learning in this area. The skills described include engagement, de-escalation, risk assessment, safety planning, conflict resolution, brief addiction counselling, linking clients with housing and community resources, advocacy, challenging systemic racism, relationship building, and documentation with awareness of relevant legislation. When applied within police co-response programs, these skills can contribute to harm prevention and reduction efforts and offer hope to clients in crisis. Broader structural change is needed to address deeply rooted social problems such as racism and stigma, though social workers on MCITs can endeavor to address systemic gaps in care for disadvantaged groups. Ongoing program evaluation is crucial to determining whether MCITs are meeting the needs of communities, families, and clients in crisis and further research is needed to identify social work skills which can predict desired outcomes.

Acknowledgements Assistance provided by Professor Eliana Suarez with the Wilfrid Laurier Faculty of Social Work is greatly appreciated.

Funding This research is financially supported by the Canadian Social Science and Humanities Research Council (SSHRC). 


\section{Declarations}

Conflict of interest The author declares no conflict of interest with respect to the authorship and/or publication of this article.

Ethical approval Research included in this manuscript has not involved human subjects and does not require REB/IRB approval.

\section{References}

ACLU. (2020). The other epidemic: Fatal police shootings in the time of COVID-19. American Civil Liberties Union. https://www.aclu. org/sites/default/files/field_document/aclu_the_other_epidemic_ fatal_police_shootings_2020.pdf

Adhopia, V. (2020, July 4). It's time to rethink police wellness checks, mental health advocates say. $C B C$ News. https://www.cbc.ca/ news/health/police-wellness-check-alternatives-1.5637169

Allan, B., \& Smylie, J. (2015). First Peoples, Second Class Treatment: The role of racism in the health and well-being of Indigenous peoples in Canada (p. 71). Wellsley Institute. https://www.welle sleyinstitute.com/wp-content/uploads/2015/02/Full-ReportFPSCT-Updated.pdf

American Psychiatric Association. (2013). Diagnostic and Statistical Manual of Mental Disorders (DSM-5®). American Psychiatric Pub.

American Psychiatric Association. (2015). The American Psychiatric Association Practice Guidelines for the Psychiatric Evaluation of Adults (Third). American Psychiatric Pub.

Armstrong, L. (2020, May 9). More drinking, more pot use and fewer avenues to get help-The 'forgotten crisis' within COVID-19. The Toronto Star. https://www.thestar.com/news/gta/2020/05/09/ more-drinking-more-pot-use-and-fewer-avenues-to-get-help-theforgotten-crisis-within-covid-19.html

Bailey, K., Paquet, S. R., Ray, B. R., Grommon, E., Lowder, E. M., \& Sightes, E. (2018). Barriers and facilitators to implementing an urban co-responding police-mental health team. Health \& Justice, 6(1), 21. https://doi.org/10.1186/s40352-018-0079-0

BEAM. (2017). Mobile crisis units by state. BEAM. https://www. beam.community/mobilecrisis

Betteridge, L. (2013). Practice notes: Meeting professional obligations and protecting clients' privacy: Disclosure of information without consent. Ontario College of Social Workers and Social Service Workers. https://www.ocswssw.org/wp-content/uploads/ 2015/01/PN-Meeting-Professional-Obligations.pdf

Blais, E., Landry, M., Elazhary, N., Carrier, S., \& Savard, A.-M. (2020). Assessing the capability of a co-responding policemental health program to connect emotionally disturbed people with community resources and decrease police use-of-force. Journal of Experimental Criminology. https://doi.org/10.1007/ s11292-020-09434-x

Boyd, G. (2001). The drug war is the new Jim Crow. American Civil Liberties Union. https://www.aclu.org/other/ drug-war-new-jim-crow

Bretneff, B. (2020, June 24). Police wellness checks: Why they're ending violently and what experts say needs to change. Global News. https://globalnews.ca/news/7092621/police-wellness-checksexperts-change/

Brodsky, B. S., Spruch-Feiner, A., \& Stanley, B. (2018). The zero suicide model: Applying evidence-based suicide prevention practices to clinical care. Frontiers in Psychiatry. https://doi.org/10. 3389/fpsyt.2018.00033

Bronskill, J. (2020, August 14). Police chiefs embrace health-led response to dealing with people in mental crisis I CBC News.
CBC News. https://www.cbc.ca/news/politics/police-chiefspublic-saftey-committee-1.5687491

Bullimore, P. (2013). The relationship between trauma and paranoia: Managing paranoia. In M. Romme \& S. Escher (Eds.), Psychosis as a personal crisis (pp. 67-79). Routledge/Taylor \& Francis Group.

CASW. (2005a). CASW: Code of ethics. Canadian Association of Social Workers. https://www.casw-acts.ca/files/documents/ casw_code_of_ethics.pdf

CASW. (2005b). Guidelines for ethical practice (p. 40). Canadian Association of Social Workers.

CDC. (2018, December 19). Infographic: 6 guiding principles to a trauma-informed approach. Center Disease Control and Prevention. https://www.cdc.gov/cpr/infographics/6_principles_ trauma info.htm

Chaimowitz, G. (2012). The criminalization of people with mental illness. Canadian Journal of Psychiatry, 57(2), 1-6.

CIHI. (2021). 1 in 10 Canadians wait 4 months or more before receiving community mental health counselling. Canadian Institute for Health Information. https://www.cihi.ca/en/1-in10-canadians-wait-4-months-or-more-before-receiving-commu nity-mental-health-counselling

Climber, B. A., \& Gicker, B. (2021). CAHOOTS: A model for prehospital mental health crisis intervention. Psychiatric Times, $38(1)$.

CMHA Ontario. (2012). Violence and mental health: Unpacking a complex issue. Canadian Mental Health Association - Ontario. https://ontario.cmha.ca/documents/violence-and-mental-healthunpacking-a-complex-issue/

CMHA Ontario. (2014). Mobile crisis rapid response team-A first for Ontario. https://ontario.cmha.ca/news/mobile-crisis-rapid-respo nse-team-first-ontario/

CMHA Ontario. (2018). Harm reduction. Canadian Mental Health Association - Ontario. https://ontario.cmha.ca/harm-reduction/

Coid, J. W., Ullrich, S., Bebbington, P., Fazel, S., \& Keers, R. (2016). Paranoid ideation and violence: Meta-analysis of individual subject data of 7 population surveys. Schizophrenia Bulletin, 42(4), 907-915. https://doi.org/10.1093/schbul/sbw006

Conroy, S., Burczycka, M., \& Savage, L. (2019). Family violence in Canada: A statistical profile, 2018 (p. 62). Statistics Canada.

Corrigan, P. W., \& Watson, A. C. (2002). Understanding the impact of stigma on people with mental illness. World Psychiatry, 1(1), 16-20.

Dattilio, F. M., \& Freeman, A. (Eds.). (2010). Cognitive-behavioral strategies in crisis intervention, Third Edn. The Guilford Press.

Dawson, M., \& Piscitelli, A. (2017). Risk factors in domestic homicides: Identifying common clusters in the Canadian context. Journal of Interpersonal Violence, 1(1), 1-12. https://doi.org/ $10.1177 / 0886260517729404$

de Shazer, S., \& Dolan, Y. (2007). More than miracles: The state of the art of solution-focused brief therapy (1 Ed.). Routledge.

Desilver, D., Lipka, M., \& Fahmy, D. (2020). 10 things we know about race and policing in the U.S. Pew Research Center. https://www. pewresearch.org/fact-tank/2020/06/03/10-things-we-knowabout-race-and-policing-in-the-u-s/

Dixon, L. B., Holoshitz, Y., \& Nossel, I. (2016). Treatment engagement of individuals experiencing mental illness: Review and update. World Psychiatry, 15(1), 13-20. https://doi.org/10.1002/wps. 20306

Dupont, R., Cochran, M. S., \& Pillsbury, S. (2007). Crisis intervention team core elements (p. 20). University of Memphis. http://cit. memphis.edu/pdf/CoreElements.pdf

Fahim, C., Semovski, V., \& Younger, J. (2016). The Hamilton mobile crisis rapid response team: A first-responder mental health service. Psychiatric Services, 67(8), 929-929. https://doi.org/10. 1176/appi.ps.670802 
Fazel, S., Gulati, G., Linsell, L., Geddes, J. R., \& Grann, M. (2009). Schizophrenia and violence: Systematic review and meta-analysis. PLOS Medicine, 6(8), e1000120. https://doi.org/10.1371/ journal.pmed.1000120

FCM. (2020). Making housing affordable for all. Federation of Canadian Municipalities. https://fcm.ca/en/focus-areas/housing/making-housing-affordable

Franklin, C., Trepper, T. S., McCollum, E. E., \& Gingerich, W. J. (Eds.). (2011). Solution-focused brief therapy: A handbook of evidence-based practice. Oxford University Press.

Fry, H., Van Loon, P., Nantel, P., Breton, P., Casey, S., Dabrusin, J., Dhillon, A., Dzerowicz, J., \& Virani, A. (2018). Taking action against systemic racism and religious discrimination including Islamophobia (p. 130). Standing Committee on Canadian Heritage. https://www.ourcommons.ca/Content/Committee/421/ CHPC/Reports/RP9315686/chpcrp10/chpcrp10-e.pdf

Fuller, D. A., Lamb, H. R., Biasotti, M., \& Snook, J. (2015). Overlooked in the Undercounted: The role of mental illness in fatal law enforcement encounters. (p. 27). Treatment Advocacy Center.

Hagen, R. (Ed.). (2011). CBT for psychosis: A symptom-based approach. Routledge.

Halwani, S. (2004). Racial inequality in access to health care services. Ontario Human Rights Commission.

Houghton, K. (2021, June 10). In Montana, Crisis Support Teams ***offer alternatives to policing mental health. NPR. https:// www.npr.org/sections/health-shots/2021/06/10/1004744348/ in-montana-crisis-support-teams-offer-alternatives-to-polic ing-mental-health

Hughes, P. (2020, June 30). From Discrimination to Systemic Racism: Understanding Societal Construction [SLAW]. http://www.slaw. ca/2020/06/30/from-discrimination-to-systemic-racism-under standing-societal-construction/

Iacobucci, F. (2014). Police encounters with people in crisis (Report). Toronto Police Service. https://www.torontopolice.on.ca/publi cations/files/reports/police_encounters_with_people_in_crisis_ 2014.pdf

IACP. (2016). Improving police response to persons affected by mental illness (p. 28). International Association of Chiefs of Police.

James, R. K., \& Gilliland, B. E. (2016). Crisis Intervention Strategies. Nelson Education.

Kirst, M., Pridham, K. F., Narrandes, R., Matheson, F., Young, L., Niedra, K., \& Stergiopoulos, V. (2015). Examining implementation of mobile, police-mental health crisis intervention teams in a large urban center. Journal of Mental Health, 24(6), 369-374. https://doi.org/10.3109/09638237.2015.1036970

Kisely, S., Campbell, L. A., Peddle, S., Hare, S., Pyche, M., Spicer, D., \& Moore, B. (2010). A controlled before-and-after evaluation of a mobile crisis partnership between mental health and police services in Nova Scotia. Canadian Journal of Psychiatry, 55(10), 662-668. https://doi.org/10.1177/070674371005501005

Lamanna, D., Kirst, M., Shapiro, G., Matheson, F., Nakhost, A., \& Stergiopoulos, V. (2015). Toronto Mobile Crisis Intervention Team (MCIT): Outcome evaluation report. Centre for Research on Inner City Health, 58.

Lamanna, D., Shapiro, G. K., Kirst, M., Matheson, F. I., Nakhost, A., \& Stergiopoulos, V. (2018). Co-responding police-mental health programmes: Service user experiences and outcomes in a large urban centre. International Journal of Mental Health Nursing, 27(2), 891-900. https://doi.org/10.1111/inm.12384

Large, M. M., \& Nielssen, O. (2011). Violence in first-episode psychosis: A systematic review and meta-analysis. Schizophrenia Research, 125(2), 209-220. https://doi.org/10.1016/j.schres. 2010.11.026

Lego, S. (Ed.). (1984). American handbook of psychiatric nursing. Lippincott Williams \& Wilkins.
Linehan, M. M. (2014). DBT skills training manual, Second Edition (Second Edition, Available separately: DBT skills training handouts and worksheets, Second edition). The Guilford Press.

Ling, J. (2020, June 30). Psychiatric teams, not the police, should be responding to mental-health calls. National Post. https:// nationalpost.com/opinion/justin-ling-psychiatric-teams-notthe-police-should-be-responding-to-mental-health-calls

Livingston, J. D. (2013). Mental illness-related structural stigma: The downward spiral of systemic exclusion final report (p. 50). Mental Health Commission of Canada. https://www.menta lhealthcommission.ca/sites/default/files/MHCC_OpeningMin ds_MentalIllness-RelatedSructuralStigmaReport_ENG_0_0. pdf

Lord, V. B., \& Bjerregaard, B. (2014). Helping persons with mental illness: Partnerships between police and mobile crisis units. Victims \& Offenders, 9(4), 455-474. https://doi.org/10.1080/15564 886.2013.878263

Marcoux, J., \& Nicholson, K. (2018, April 5). Deadly force. CBC News. https://newsinteractives.cbc.ca/longform-custom/deadly-force

Maxwell, W. (2003). The use of gallows humor and dark humor during crisis situation. International Journal of Emergency Mental Health, 5(2), 93-98.

Maynard, R. (2017). Policing black lives: State violence in Canada from slavery to the present. Fernwood Publishing. https://www. amazon.ca/Policing-Black-Lives-Violence-Slavery/dp/15526 69793

Mental Health Act, c. M.7 R.S.O. (1990). https://www.ontario.ca/laws/ view

Mental Health in America. (2021). The state of mental health in America. Mental Health in America. https://www.mhanational.org/ issues/state-mental-health-america

Mereli, F. (2020, September 17). Toronto police pushing to expand mobile crisis team to respond to mental health calls. CBC News. https://www.cbc.ca/news/canada/toronto/toronto-police-set-toexpand-mobile-crisis-intervention-team-1.5726548

Miller, W. R., \& Rollnick, S. (2012). Motivational interviewing, Third Edition: Helping people change (Third edition). The Guilford Press.

Morabito, M. S. (2007). Horizons of context: Understanding the police decision to arrest people with mental illness. Psychiatric Services (washington, d.c.), 58(12), 1582-1587. https://doi.org/10.1176/ appi.ps.58.12.1582

Mullaly, B., \& Dupré, M. (2018). The new structural social work: Ideology, theory, and practice. Oxford University Press.

Najavits, L. (2002). Seeking safety: A treatment manual for PTSD and substance abuse. Guilford Press.

NAMI. (2016). Engagement: A new standard for mental health care. National Alliance for Mental Illness. https://www.nami.org/ Support-Education/Publications-Reports/Public-Policy-Repor ts/Engagement-A-New-Standard-for-Mental-Health-Care/ NAMI_Engagement_Web\#: :text=Engagement $\% 20$ is $\% 20$ the $\%$ 20strengths $\% 2$ Dbased,of $\% 20$ family $\% 2$ C $\% 20$ culture $\% 20$ and $\%$ 20community.

NASW. (2017). Revised code of ethics. National Associacion of Social Workers. https://www.socialworkers.org/About/Ethics/Code-ofEthics/Code-of-Ethics-English

OCSWSSW. (2011). Code of ethics and standards of practice handbook 2nd Edn. Ontario College of Social Workers and Social Service Workers. https://www.ocswssw.org/wp-content/uploads/ 2015/01/Code-of-Ethics-Standards-of-Practice.pdf

OHRC. (2020a). A disparate impact: Second interim report on the inquiry into racial profiling and racial discrimination of Black persons by the Toronto Police Service. Ontario Human Rights Commission. http://www3.ohrc.on.ca/en/disparate-impact-second-interim-report-inquiry-racial-profiling-and-racial-discrimina tion-black 
OHRC. (2020b). Racism and racial discrimination: Systemic discrimination (fact sheet). Ontario Human Rights Commission. http://www3.ohrc.on.ca/en/racism-and-racial-discriminationsystemic-discrimination-fact-sheet

O’Neill, M. (2020, June 12). Opinion: Canada has a long, documented history of racism and racial discrimination. Don't look away. Globe and Mail. https://www.theglobeandmail. com/opinion/article-canada-has-a-long-documented-histo ry-of-racism-and-racial/

Owen, B. (2020, June 28). Recent deaths prompt calls for new way to respond to mental health crises in Canada. CP24. https://www. cp24.com/news/recent-deaths-prompt-calls-for-new-way-torespond-to-mental-health-crises-in-canada- 1.5003222 ?cache $=$ emuosurrypzum $\% 3$ FcontactForm $\% 3$ Dtrue

Patterson, G. T. (2004). Police-social work crisis teams: Practice and research implications. Stress, Trauma, and Crisis, 7(2), 93-104. https://doi.org/10.1080/15434610490450886

Patterson, G. T., \& Swan, P. G. (2019). Police social work and social service collaboration strategies one hundred years after Vollmer: A systematic review. Policing: an International Journal, 42(5), 863-886. https://doi.org/10.1108/PIJPSM-06-2019-0097

Prochaska, J. O., \& Norcross, J. C. (2007). Changing for good: A revolutionary six-stage program for overcoming bad habits and moving your life positively forward (REP edition). William Morrow Paperbacks.

Puntis, S., Perfect, D., Kirubarajan, A., Bolton, S., Davies, F., Hayes, A., Harriss, E., \& Molodynski, A. (2018). A systematic review of co-responder models of police mental health 'street' triage. $B M C$ Psychiatry. https://doi.org/10.1186/s12888-018-1836-2

Ramsay, R. F. (2004). Suicide Intervention Handbook (10th Edn.). Livingworks.

Regehr, C. (2011). Crisis theory and social work treatment. In Social work treatment: Interlocking theoretical approaches (5th Edn, pp. 134-143). Oxford University Press

Regehr, C., \& Glancy, G. (2014). Mental health social work practice in Canada (Second Edn). Oxford University Press.

Reston, M. (2021). Analysis: Optimism on police reform in the Capitol collides with anguish in the streets. CNN. https://www.cnn.com/ 2021/04/25/politics/joe-biden-police-reform-congress/index.html

Roberts, A. R. (1978). Training police social workers: A neglected area of social work education. Journal of Education for Social Work, 14(2), 98-103. https://doi.org/10.1080/00220612.1978.10671506

Roberts, A. R. (2000). An overview of crisis theory and crisis intervention. In A. Roberts (Ed.), Crisis Intervention Handbook: Assessment, Treatment, and Research (2nd ed., pp. 3-30). Oxford University Press.

Roberts, A. R., \& Ottens, A. J. (2005). The seven-stage crisis intervention model: A road map to goal attainment, problem solving, and crisis resolution. Brief Treatment and Crisis Intervention, 5(4), 329. https://doi.org/10.1093/brief-treatment/mhi030

Sam, Y. (2020, August 27). Defunding police isn't the answer, there's a fundamental imbalance that must be fixed. CBC News. https:// www.cbc.ca/news/opinion/opinion-police-defunding-reform-1. 5679173

SAMHSA. (2020). Considerations for the care and treatment of mental and substance use disorders in the COVID-19 epidemic (p. 1). Substance Abuse and Mental Health Services Administration. https://www.samhsa.gov/sites/default/files/considerations-caretreatment-mental-substance-use-disorders-covid19.pdf

Saunders, M. (2016). Crisis Intervention and De-escalation Techniques. http://www.cit.memphis.edu/modules/De-Escalation/ presentations/FL\%20-\%20De\%20Escalation\%20Techniques.pdf

Semple, T., Tomlin, M., Bennell, C., \& Jenkins, B. (2020). An evaluation of a community-based mobile crisis intervention team in a small Canadian police service. Community Mental Health Journal, 57, 567-578. https://doi.org/10.1007/s10597-020-00683-8
Singh, I. (2020, July 23). Deadly force. CBC News. https://newsintera ctives.cbc.ca/fatalpoliceencounters

Solly, M. (2020). 158 Resources for understanding systemic racism in America. Smithsonian Magazine. https://www.smithsonia nmag.com/history/158-resources-understanding-systemic-racism-america-180975029/

Solomon, D., Maxwell, C., \& Castro, A. (2019). Systemic inequality: Displacement, exclusion, and segregation. Center for American progress. https://www.americanprogress.org/issues/race/repor ts/2019/08/07/472617/systemic-inequality-displacement-exclu sion-segregation/

Statistics Canada. (2015, June 2). Mental health and contact with police in Canada. Government of Canada. https://www150.statc an.gc.ca/n1/pub/85-002-x/2015001/article/14176-eng.htm\#a1

Steadman, H. J., \& Morrissette, D. (2016). Police responses to persons with mental illness: Going beyond CIT training. Psychiatric Services, 67(10), 1054-1056. https://doi.org/10.1176/appi.ps.20160 0348

Takeuchi, A., Ahern, T. L., \& Henderson, S. O. (2011). Excited delirium. Western Journal of Emergency Medicine, 12(1), 77-83.

Talbot, L. A., \& Lumden, D. B. (1999). On the association between humor and burnout. International Journal of Humor Research, 13(4), 419-428. https://doi.org/10.1515/humr.2000.13.4.419

Toronto City Council. (2020, June 30). CC22.2 City council consideration on June 29, 2020: Changes to Policing in Toronto. City Council Decision. http://app.toronto.ca/tmmis/viewAgenda ItemHistory.do?item $=2020$. CC 22.2

Torrey, E. F., Dailey, J., Lamb, H. R., Sinclair, E., \& Snook, J. (2017). Treat or repeat: A survey of serious mental illness, major crimes and community treatment. Treatment Advocacy Center. https:// www.treatmentadvocacycenter.org/storage/documents/treat-orrepeat.pdf

TRC. (2015). Honouring the truth, reconciling for the future: Summary of the final report of the truth and reconciliation Commission of Canada (p. 536). Truth and Reconciliation Commission of Canada.

Tunney, C. (2020a, June 23). Number of mental health calls Mounties respond to growing exponentially, Lucki says. CBC News. https:// www.cbc.ca/news/politics/lucki-blair-policing-study-committee1.5624189

Tunney, C. (2020b, August 30). Watchdog lifts lid on investigation reports raising red flags about RCMP actions. CBC News. https:// www.cbc.ca/news/politics/rcmp-watchdog-investigations-summa ries- 1.5700470

Turner, P. M., \& Turner, T. J. (1991). Validation of the crisis triage rating scale for psychiatric emergencies. Canadian Journal of Psychiatry, 36(9), 651-654. https://doi.org/10.1177/0706743791 03600905

Usher, L., Watson, A. C., Bruno, R., Andriukaitis, S., Kamin, D., Speed, C., \& Taylor, S. (2019). Crisis Intervention Team (CIT) Programs: A best practice guide for transforming community responses to mental health crisis (p. 244). CIT International. https://www.citinternational.org/bestpracticeguide

Van Sickle, C. (2018). Practice notes: Communication technology practices and policies for a digital world (p. 7). OCSWSSW: Ontario College of Social Workers and Social Service Workers.

Vancouver Police Department. (2020). Police community response team. Vancouver Police Department. https://vancouver.ca/police/ organization/investigation/investigative-support-services/youthservices/community-response.html

Ventura, J., Nuechterlein, K. H., Subotnik, K. L., Gutkind, D., \& Gilbert, E. A. (2000). Symptom dimensions in recent-onset schizophrenia and mania: A principal components analysis of the 24-item Brief Psychiatric Rating Scale. Psychiatry Research, 97(2-3), 129-135. https://doi.org/10.1016/s0165-1781(00) 00228-6 
Watson, A. C., Compton, M. T., \& Draine, J. N. (2017). The crisis intervention team (CIT) model: An evidence-based policing practice? Behavioral Sciences \& the Law, 35(5-6), 431-441. https://doi.org/10.1002/bsl.2304

Watson, A. C., \& Fulambarker, A. J. (2012). The crisis intervention team model of police response to mental health crises: A primer for mental health practitioners. Best Practices in Mental Health, $8(2), 71$.

Westervelt, E. (2020, September 18). Mental health and police violence: How crisis intervention teams are failing. NPR. https:// www.npr.org/2020/09/18/913229469/mental-health-and-policeviolence-how-crisis-intervention-teams-are-failing

Yeager, K., \& Roberts, A. (Eds.). (2015). Crisis intervention handbook: Assessment, treatment, and research (4th ed.). Oxford: Oxford University Press.
Publisher's Note Springer Nature remains neutral with regard to jurisdictional claims in published maps and institutional affiliations.

Amar Ghelani is a registered social worker with the University of Toronto Health and Counselling Centre and PhD Candidate with the Wilfrid Laurier University Faculty of Social Work. He has worked as a full time Crisis Intervention Specialist with a Canadian Police Service and Mobile Crisis Intervention Team. 